\title{
PHÁT TRIỂN CHƯƠNG TRİ̀H GIÁO DỤC ĐẠI HỌC ĐÁP ÚNG YÊU CẦU NHÂN LỤ̉C THỜI KỲ CÔNG NGHIỆP 4.0
}

\author{
NGUYỄN THIÊN TUÊ \\ Truờng Đại học Công nghiệp Thành phố Hồ Chí Minh; \\ nguyenthientue@iuh.edu.vn
}

Tóm tắt. Nhân loại đã bước vào cuộc cách mạng công nghiệp lần thứ tư (cách mạng công nghiệp 4.0). Cuộc cách mạng này đặt ra yêu cầu mới về nguồn nhân lực ở mọi quốc gia, lãnh thổ trên toàn thế giới. Với trọng trách đào tạo nguồn nhân lực, nghiên cứu khoa học và phát triển công nghệ; các cơ sở giáo dục đại học phải có những quyết sách như thế nào về phát triển (xây dựng hoặc thiết kế) chương trình đào tạo để nguồn nhân lực được đào tạo đáp ứng các yêu cầu cách mạng công nghiệp 4.0.

Từ khóa. Giáo dục đại học, chương trình, nhân lực, công nghiệp 4.0

\section{DESIGNING HIGHER EDUCATION CURRICULA RESPONDING TO HUMAN NEED OF "INDUSTRY 4.0"}

\begin{abstract}
Human beings are entering the 4th industrial revolution "Industry 4.0". This revolution has raised a human resource demand to all countries and regions in the world. With the mission of training, conducting research, and technology development, all higher education institutions are facing with the problem of how to design (or develop) training curricula appropriately that respond to the needs of "Industry 4.0".
\end{abstract}

Keywords. Higher education, curriculum, manpower, Industry 4.0

\section{1. ĐẶC TRƯNG CỦA CUỘC CÁCH MẠNG CÔNG NGHIÊP 4.0}

Nhân loại đã trải qua các cuộc cách mạng công nghiệp: Cuộc cách mạng công nghiệp lần thứ nhất đã diễn ra vào thập niên 80 của thế kỷ 18 (1784) đến gần nửa đầu thế kỷ 19, với sự thay đổi tù̀ nền sản xuất thủ công đến nền sản xuất cơ khi nhờ động co hơ nước. Cuộc cách mạng công nghiệp lần thứ hai đã diễn ra vào nửa cuối thế kỷ 19 (1870) đến khi xảy ra Thế chiến thứ nhất (năm 1914) với sự thay đổi tù nền sản xuất theo quy mô nhỏ lẻ sang nền sản xuất quy mô lớn bằng các thiết bị chạy bằng năng lương điện. Cuộc cách mạng công nghiệp lần thứ ba đã diễn ra từ những năm 1970 của thế kỷ 20 với nền sản xuát được bán tụ động hoá dụa vào máy tính, các thiết bị điện tư và Internet. Từ những năm đầu thế kỷ 21 , nhân loại đã bước vào cuộc cách mạng công nghiệp lần thứ 4 (cách mạng công nghiệp 4.0) với nền sản xuất được tích hợp giữa các lĩnh vực vật lý, kỹ thuật số và công nghệ sinh học để giải quyết những vấn đề kinh tế - xã hội. Trong đó:

- Về Vật lý: Với robot thế hệ mới, máy in 3D, xe tự lái, các vật liệu mới và công nghệ Nano;

- Về Kỹ thuật số: Trí tuệ nhân tạo (AI), Vạn vật kết nối - Internet of Things (IoT) và Dữ liệu lớn (Big Data);

- Về Công nghệ sinh học: Tập trung vào việc nghiên cứu để tạo ra những bước nhảy vọt trong nông nghiệp, thủy sản, $\mathrm{y}$ dược, chế biến thực phẩm, bảo vệ môi trường, năng lượng tái tạo, ...

Sự tích hợp giữa các lĩnh vực trên đã tạo nên bước đột phá mới về khoa học và công nghệ, xuất hiện các mô hình mới trong sản xuất và thương mại, làm thay đồi cục diện, phương thức sản xuất và phương pháp quản trị truyền thống. Từ đó các yêu cầu về số lượng, cơ cấu, phẩm chất và năng lực của lực lượng lao động xã hội cũng phải thay đổi để thích ứng với nhu cầu sử dụng nguồn nhân lực của thời đại.

\section{YÊU CẦU NĂNG LỰC CỦA NGUỒN NHÂN LỰC TRONG THỜI KỲ CÔNG NGHIÊP 4.0}

Nếu như trong thời kỳ từ cuộc cách mạng công nghiệp lần thứ ba, nguồn nhân lực phải đạt chuẩn các yêu cầu về năng lực là có phẩm chất đạo đức, kiến thức và kỹ năng thích ứng với nền sản xuất lớn, bán tự 
động hoá dựa vào máy tính, các thiết bị điện tử; thì trong thời đại cách mạng công nghiệp 4.0, cần phải có nguồn nhân lực với các yêu cầu về năng lực như sau:

- Năng lực nghiên cứu cơ bản phát triển công nghệ số nhằm tạo ra các nguyên lý, lý thuyết cơ bản trong các lĩnh vực khoa học nói chung và đặc biệt là phát triển công nghệ số. Để có nguồn nhân lực này, cần phải chú trọng đào tạo tinh hoa mang tính hàn lâm trong các co sở giáo dục đại học với định hướng nghiên cưu.

- Năng lực nghiên cứu ứng dụng để từ các thành quả nghiên cứu cơ bản về phát triển công nghệ số mà chế tạo được các thiết bị siêu thông minh với trí tuệ nhân tạo nhằm phân tích dữ liệu lớn (big data analytics) và kết nối vạn vật. Để có nguồn nhân lực này, cần phải đẩy mạnh đào tạo ưng dụng trong các cơ sở giáo dục đại họ với định hướng ứng dụng.

- Năng lực làm chủ việc điều khiển các thiết bị siêu thông minh trong các hoạt động giao tiếp xã hội, nghiên cứu khoa học, phát triển công nghệ, sản xuất, thương mại, văn hoá, giáo dục, $\mathrm{y}$ tế, an ninh và quốc phòng ... nhằm đáp ứng nhu cầu đa dạng của con người trong các hoạt động của con người trong thời đại văn minh. Để có nguồn nhân lực này, phải tập trung đào tạo theo hướng liên thông và đa ngành trong các co sở giáo duc đại học theo định hướng ứng dụng.

- Năng lực quản trị hệ thống vạn vật kết nối, mà chủ yếu là quản trị được sự kết nối các thiết bị siêu thông minh, để tạo có mối liên giữa các thực thể trong một "thế giới phẳng" với nhau và với con người trên các phương diện toàn cầu, trong các khu vực, ở một quốc gia hoặc địa phương. Để có nguồn nhân lực này, trong moi cơ sở giáo dục đại học (kể cả theo định hướng nghiên cứu, theo định hướng ứng dụng) đều phải trang bị cho người được đào tạo các tri thức về quản lý hệ thống vạn vật kết nối.

Việc phân định các yêu cầu năng lực và phân định vai trò của các cơ sở giáo dục đại học nêu trên chỉ là tương đối; trong thực tiễn các yêu cầu và vai trò đó luôn giao thoa và hổ trợ cho nhau để tạo nên một chỉnh thể của nguồn nhân lực xã hội.

\section{PHÁT TRIỂN CHƯƠNG TRÌNH GIÁO DỤC ĐẠI HỌC TRONG THỜI KỲ CÔNG NGHIÊP 4.0}

Yêu cầu chung về đào tạo nguồn nhân lực trình độ đại học trong thời đại ngày nay là triển khai các hoạt động giáo dục đại học trong một nền giáo dục thông minh. Nền giáo dục đó có các yếu tố mục tiêu, nội dung chương trình, phương pháp và hình thức tổ chức, phương tiện và điều kiện, đánh giá kết quả; trong đó cốt lõi là chương trình đào tạo. Nền giáo dục đó vừa dựa trên các thành tựu của cách mạng công nghiệp 4.0 vừa nhằm vào mục tiêu phát triển nguồn nhân lực cho phát triển $\mathrm{KT}-\mathrm{XH}$ của nhân loại trong thời đại cách mạng công nghiệp 4.0. Bài viết này tập trung vào định hướng phát triển chương trình đào tạo trình độ đại học trên cơ sở quyền tự chủ của cơ sở giáo dục đại học, đồng thời vận dụng có chọn lọc cách thức xây dựng chương trình giáo dục đại học ở một số nước phát triển trên thế giới sao cho phù hợp với thực tiễn Việt Nam.

\section{a) Mục dích yêu cầu}

Tác động của cách mạng công nghiệp 4.0 làm thay đổi mọi ngành nghề trong xã hội và đòi hỏi những năng lực mới của người lao động cần thích ứng với chuyển đổi nghề nghiệp. Nếu nhà trường trang bị cho sinh viên kiến thức chuyên môn hẹp theo truyền thống thì khi ra trường họ khó tìm việc làm hoặc khó chuyển đổi nghề nghiệp. Vì vậy, khi thiết kế chương trình đào tạo cần tập trung vào các mục tiêu và đáp ứng các yêu cầu sau đây:

- Trang bị cho người học những kiến thức rộng, vừa đáp ứng tính chuyên ngành đào tạo, vừa đáp ứng tính liên ngành về các lĩnh vực công nghệ thông tin, kỹ thuật số, mạng, ... nhằm làm cho sinh viên vừa phát triển được các năng lực chuyên biệt theo yêu cầu của chuyên ngành đào tạo; vừa phát triển được các năng lực chung, như: tư duy có hệ thống, tổng hợp, liên kết giữa thế giới thực và ảo, làm việc nhóm, hợp tác liên ngành... nhằm tạo cơ hội cho sinh viên phát triển được các năng lực nghiên cứu cơ bản, nghiên cứu ứng dụng, làm chủ các thiết bị thông minh và kết nối vạn vật ...

- Phát triển năng lực tư duy sáng tạo để thích nghi với môi trường và các yêu cầu nghề nghiệp luôn thay đổi của thị trường lao động trong nước và quốc tế nhằm tránh nguy cơ mất việc làm.

- Phát triển năng lực tư duy độc lập và năng lực ra quyết định dựa trên khả năng thu thập, phân tích, phán đoán các cơ sở dữ liệu. 


\section{b) Cấu trúc chuơng trình}

Theo mô hình Giáo dục khai phóng (Tạm dịch cụm từ: Liberal Arts Education) hiện nay đang được áp dụng rộng rãi tại Hoa Kỳ và một số quốc gia phát triển trên thế giới; thì đặc trưng nổi bật của chương trình đào tạo đại học là tính linh hoạt, là chú trọng cả chiều rộng và chiều sâu đối với mục tiêu đào tạo, khuyến khích các môn học liên ngành, tăng cường khả năng lựa chọn nhằm tạo điều kiện để sinh viên ra trường có đủ các năng lực để thích nghi được với môi trường làm việc cũng như có khả năng học hỏi trong các lĩnh vực nghiên cứu đa dạng nhờ vào những kiến thức nền tảng [3]. Vì vậy, khi thiết kế chương trình đào tạo cần phân bổ hợp lý: về thời lượng, về số môn học ở từng khối kiến thức (Giáo dục đại cương, Giáo dục chuyên nghiệp (cơ sở ngành và chuyên ngành), về tỉ lệ lý thuyết với thực hành và thí nghiệm; về tî̉ lệ các môn học tự chọn trong mỗi khối kiến thức. Trong đó:

- Khối kiến thức giáo dục đại cương, còn gọi là giáo dục tổng quát (General Education) cần tập trung trang bị rộng cho sinh viên về các kiến thức và kỹ năng cơ bản. Trong đó có hai nhóm: thứ nhất là nhóm các môn khoa học cơ bản gồm những môn học trang bị các kiến thức và kỹ năng nền tảng cho sinh viên học tiếp các môn chuyên chuyên ngành; ví dụ như toán, lý, hóa, ...; thứ hai là nhóm các môn học trang bị kiến thức hiểu biết chung về triết học, kinh tế học, luật học, nhà nước, thể chế, văn hóa, nghệ thuật...

Qua nghiên cứu một số chương trình giáo dục đại học các nước tiên tiến, đặc biệt là của Hoa kỳ, thời lượng dành cho khối kiến thức Giáo dục đại cương chiếm tỉ lệ khoảng $35-40 \%$ thời lượng của chương trình khoá học. Trên thực tế, chương trình giáo dục đại học của Việt Nam cũng có tỉ lệ như vậy; tuy nhiên cơ cấu các môn học còn cứng nhắc và hầu như rất ít các môn học tự chọn. Chính vì vậy, cần cơ cấu lại các môn học theo hướng đa dạng, đồng thời đưa vào nhiều môn học tự chọn để sinh viên có cơ hội được trang bị các kiến thức nền tảng trước khi bước vào học các môn chuyên ngành.

- Khối kiến thức giáo dục chuyên nghiệp gồm có hai phần: cơ sở ngành (nhóm ngành) và chuyên ngành. Về thời lượng, ở Việt Nam, khối này chiếm tỉ lệ khoảng $60-65 \%$ thời lượng của chương trình khoá học. Điều này không có sự khác biệt nhiều so với chương trình đào tạo ở nước ngoài; tuy nhiên, về cơ cấu, sắp xếp các môn học chưa hợp lý, hơn nữa cũng chưa phân định rõ ràng các môn học thuộc cơ sở ngành, nhóm ngành và chuyên ngành. Một sự bất cập hiện nay trong một số cơ sở giáo dục đại học ở Việt Nam là các chương trình đào tạo trong cùng khối ngành thiếu sự kết nối và chia sẻ với nhau các môn học cơ sở ngành, nhóm ngành. Đó là các môn học có cùng nội dung, nhưng chưa đồng nhất về mã môn học đã gây bất lợi cho sinh viên thực hiện nguyên vọng học nhiều ngành, chuyên ngành cùng một lúc.

Cần thực hiện sự phân bổ các khối kiến thức trong chương trình như biểu đồ sau:

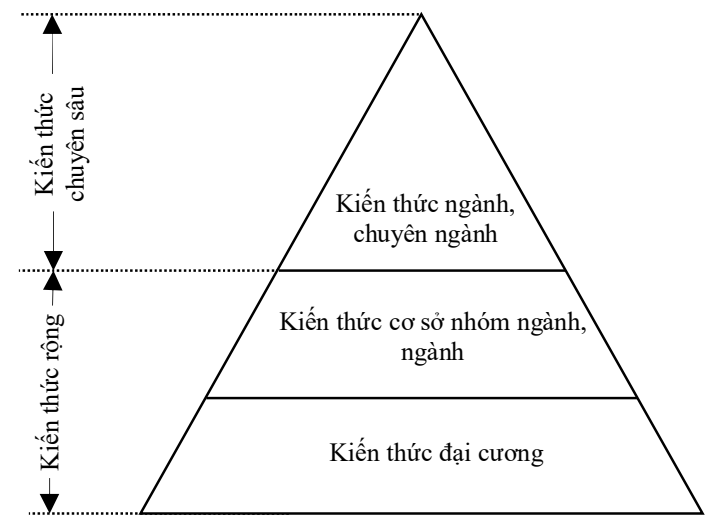

- Khối kiến thức giáo dục đại cuoong: $30-40 \%$

- Khối kiến thúc co sở nhóm ngành, ngành: 25-30\%

- Khối kiến thức ngành, chuyên ngành: $30-40 \%$

- Tăng số lượng các môn tự chọn. Về lý luận, tỉ lệ các môn tự chọn càng nhiều thì càng có lợi cho sinh viên. "Việc tự chọn là rất quan trọng để học sinh mở mang kiến thức về nhiều ngành học khác nhau. Việc hiểu biết liên ngành này cho phép học sinh hợp tác nghiên cứu liên ngành, phân tích và nhìn vấn đề không 
bị cục diện, bó hẹp vào chuyên môn của mình. Sinh viên đại học với quyền tự chọn có thể học đồng thời hai ngành, hoặc một ngành chính và một ngành phụ. Sau khi ra trường, họ có thể làm việc ở nhiều chuyên môn khác nhau chứ không bị bó vào ngành chuyên môn duy nhất mà mình học ở trường, kể cả thay đổi hoàn toàn để theo một ngành khác" [2]. Tuy nhiên, trong thực tế thì nhiều trường còn e ngại vì có khó khăn tạm thời về điều kiện tổ chức lớp học và về đội ngũ giảng viên. Vì vậy, trong điều kiện cho phép cũng cần mở rộng các môn tự chọn một cách phù hợp.

\section{c) Về nội dung}

- Bổ sung các môn học trang bị kiến thức nền tảng cho sinh viên vào các khối đào tạo. Bên cạnh môn học có mục tiêu trang bị các kiến thức về nghề nghiệp, cần mở rộng cung cấp thêm các kiến thức về các môn khoa học tự nhiên, xã hội, văn hóa, nghệ thuật..; nhằm trang bị cho sinh viên các kỹ năng khác như: giao tiếp, làm việc nhóm, tự học, tự nghiên cứu, tư duy sáng tạo... để ngoài các kỹ năng chuyên môn chính, họ có được các kỹ năng khác.

- Đảm bảo tính liên thông trên cơ sở phải đáp ứng chuẩn đầu ra của ngành đào tạo, nhưng có sự liên kết giữa các ngành học, bậc học và giữa các cơ sở giáo dục (trường đại học) trong nước và quốc tế với nhau.

Có thể thực hiện tỉ lệ giao thoa giữa nội dung trong chương trình đào tạo theo ngành và khối ngành như biểu đồ sau:

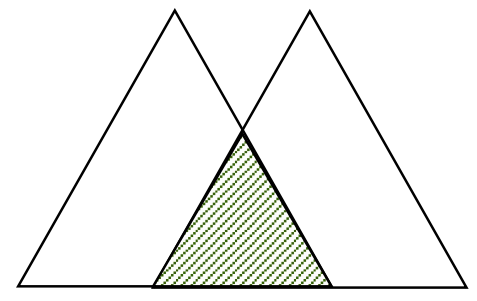

Chương trình khác lĩnh vực (khối ngành).

Tỷ lệ giao nhau: 35 - 40\%

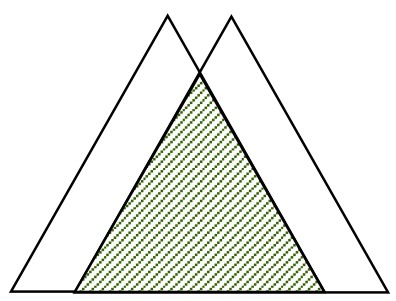

Chương trình cùng lĩnh vực. Tỷ lệ giao nhau: $60-70 \%$

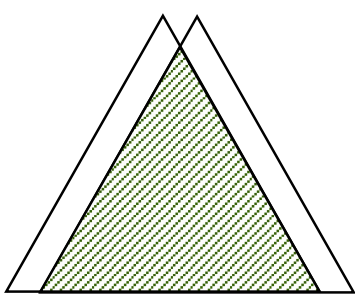

Chương trình các chuyên ngành cùng lĩnh vực.

Tỷ lệ giao nhau: $75-85 \%$

- Chương trình và giáo trình cần được tổ chức xây dựng và triển khai theo hướng mở (cho phép cập nhật thường xuyên về kiến thức trong và ngoài nước, sử dụng giáo trình, học liệu trong nước hoặc ngoài nước một cách linh hoạt để giảng dạy). Nội dung giảng dạy tuy không quy định cứng, nhưng phải phù hợp với yêu cầu thực tiễn của ngành nghề mà người học đang theo đuổi.

- Phải phân bổ hợp lý giữa lý thuyết và thực hành, thí nghiệm. Trong thời kỳ cách mạng công nghiệp 4.0, nhờ sự đột phá về KH\&CN, các thiết bị sản xuất, lưu thông hàng hoá, giao dịch thương mại, giáo dục, $\mathrm{y}$ tế... trên các bình diện tổ chức, doanh nghiệp, cộng đồng, địa phương, quốc gia và quốc tế đều dựa trên các tiện ích của công nghệ số. Nói cách khác là mọi hoạt động xã hội đều được dựa trên các thiết bị mới có các tính năng và quy trình vận hành khác với các thiết bị truyền thống. Chính vì vậy, việc thực hành và thí nghiệm cần phải đặc biệt coi trọng để sinh viên làm quen với thiết bị mới, nhận biết cấu tạo, nguyên lý và quy trình vận hành, các tiện ích của các thiết bị mới để họ sử dụng trong nghiên cứu, học tập và hành nghề. Chính vì vậy, chương trình cần phải tăng thời lượng thí nghiệm, thực hành, thực tập nghề nghiệp.

\section{KẾT LUẬn}

Nhân loại bước vào kỷ nguyên cách mạng công nghiệp 4.0 với một nền sản xuất thông minh được tích hợp từ các yếu tố: Trí tuệ nhân tạo, Vạn vật kết nối và Dữ liệu lớn. Cuộc cách mạng này đặt ra các yêu cầu mới đối với nguồn nhân lực; từ đó đòi hỏi phải có các tư duy mới trong đào tạo với một nền giáo dục thông minh. Để thích ứng với các yêu cầu của cuộc cánh mạng công nghiệp 4.0, các trường đại học phải có các tư duy mới về phát triển chương trình đào tạo nhằm trang bị cho sinh viên các năng lực thích ứng với yêu cầu cách mạng công nghiệp 4.0. 


\section{TÀI LIÊUU THAM KHẢO}

[1] Nguyễn Đức Chính, Vũ Lan Phương (2015), Phát triển chuoong trình giáo dục, NXB Giáo dục Việt Nam.

[2] Vũ Quang Việt (2005), So sánh giáo dục đại học ở Mỹ và Việt Nam, 19-7-2005.

[3] Lâm Quang Thiệp (2017), Giáo dục khai phóng (10/2017).

[4] Stuart J. Russell và Peter Norvig, Artificial Intelligence: A Modern Approach, ISBN 0-13-080302-2.

[5] Hans Moravec, Today's Computers, Intelligent Machines and Our Future, Stanford University.

Ngày nhận bài: 10/12/2017

Ngày chấp nhận đăng: 30/12/2017 